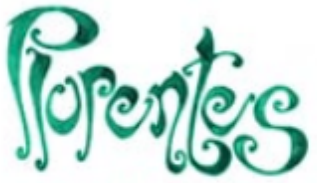

Artes y Letras
Plurentes. Artes y Letras

ISSN: 1853-6212

plurentesunlp@gmail.com

Universidad Nacional de La Plata

Secretaría de Asuntos Académicos

Prosecretaría de Asuntos Académicos

Bachillerato de Bellas Artes, "Prof. Francisco A. De Santo"

Argentina

\title{
Cultura visual, Lengua y Literatura: territorios en común
}

\author{
Gagliardi, Lucas \\ Cultura visual, Lengua y Literatura: territorios en común \\ Plurentes. Artes y Letras, núm. 11, e002, 2020 \\ Universidad Nacional de La Plata \\ Secretaría de Asuntos Académicos \\ Prosecretaría de Asuntos Académicos \\ Bachillerato de Bellas Artes, "Prof. Francisco A. De Santo" \\ Argentina \\ DOI: https://doi.org/10.24215/18536212e002
}

Atribución no comercial compartir igual (CC BY-NC-SA) 4.0 


\section{Cultura visual, Lengua y Literatura: territorios en común}

Visual culture, Language and Literature: common gronds

Lucas Gagliardi

DOI: https://doi.org/10.24215/18536212e002

Instituto de Investigación en Humanidades y Ciencias

Sociales, Centro de Estudios e Investigaciones Lingüisticas,

Universidad Nacional de La Plata / Instituto Superior de

Formación Docente y Técnica No 9, Argentina

lucas.lenguayliteratura@hotmail.com.ar

Recepción: 01 Septiembre 2020

Aprobación: 08 Septiembre 2020

Publicación: 26 Octubre 2020

\section{Resumen:}

En este trabajo revisamos las vinculaciones entre la enseñanza de la lengua y la literatura y el cuerpo de saberes que aborda la cultura visual. A partir de un breve repaso histórico de estas relaciones en el marco del sistema educativo argentino y un análisis de las directivas curriculares vigentes, proponemos una serie de ejes organizadores del trabajo docente para articular los conocimientos disciplinares en el marco de propuestas didácticas: la denotación/connotación, la estereotipia, la intertextualidad, la paratextualidad y la enunciación y retórica.

Palabras ClaVE: Didáctica, Lengua, Literatura, Cultura visual, Currículum.

\section{Abstract:}

In this article we examine links between the teaching of Language and Literature and visual culture. After a brief historical review of such links in the case of Argentina's educational system and analyzing educational policies, we will propose a series of principles with the aim of organizing educational practices and articulating knowledge from different disciplines within didactic proposals: denotation/connotation, stereotypes, intertextuality, paratextuality, enunciation and rhetoric.

KEYWORDS: Didactics, Language, Literature, Visual Culture, Currículum.

\section{INTRODUCCIóN}

En los últimos años, la idea recurrente de que la escuela debe cambiar sus prácticas por otras más "innovadoras" o "significativas" para los estudiantes se ha manifestado bajo diferentes formas. Podemos enumerar someramente entre ellas el incentivo del uso de los medios digitales (Da Porta, 2015), la gamificación, el uso de la multimodalidad o el enfoque de Aprendizaje Basado en Proyectos, aunque este último no es una novedad sino que existe por lo menos desde el escolanovismo (Davini, 2008). Además, las instituciones educativas argentinas y los programas de capacitación en el marco de políticas públicas suelen promover el trabajo conjunto entre profesores de diferentes áreas curriculares que comparten cursos. ${ }^{1}$

La alusión recurrente a las "prácticas innovadoras" en el ámbito escolar ha sido estudiada con relación a la pedagogía y el currículum por objetivos y competencias (Díaz Barriga, 2005). Más allá de las críticas a los aspectos que entrañan esas exhortaciones a innovar como un fin en sí, reconocemos que el trabajo docente (Viñao, 2002) en la actualidad muestra como necesidad y posibilidad el trabajo interdisciplinario. Como necesidad en tanto se lo promueve desde las políticas educativas y dado que muchos docentes advierten los cambios en las formas de enseñanza y aprendizaje. Como posibilidad en tanto el trabajo interdisciplinario y articulador puede generar situaciones de enseñanza y aprendizaje alternativas.

En la búsqueda de nuevas opciones didácticas se involucran los saberes disciplinares de las diferentes áreas del conocimiento. Influyen en la misma tanto las tradiciones de formación y capacitación docente como las preferencias personales de los educadores, las propuestas curriculares, las representaciones del 
educador acerca de su tarea y las condiciones materiales que hagan posible o no la vinculación entre diferentes campos del saber y espacios curriculares. En el caso particular de Lengua y Literatura, investigaciones recientes (Cuesta, 2019; López Corral y Moya, 2017) vienen demostrando la necesidad de pensar alternativas para las perspectivas de enseñanza de algunos contenidos (por ejemplo, en la enseñanza de la lengua) y la incorporación en el uso de producciones culturales distintas de las que han sido tradicionales para el espacio curricular (el texto literario, las oraciones por poner solo dos ejemplos). Estos estudios muestran el ingreso de otros “consumos culturales" (Cuesta, 2019, López Corral y Moya, 2017) al trabajo con la literatura y la lengua. Sabemos que la cultura escolar ha privilegiado la lectura y la escritura en muchas áreas (no solo la específica de Lengua y Literatura). Sin embargo, en el escenario actual no es extraño pensar que la visión de la cultura letrada aislada de otras prácticas y manifestaciones resulta un tanto añeja. La semiosis, ese proceso de negociación de sentidos y significados, se vale más que nunca del diálogo entre "texto" y otros signos, por lo cual las configuraciones visuales y audiovisuales de muchos mensajes resultan no solo productivas sino imprescindibles en ocasiones para abordar contenidos de Lengua y Literatura. Ahora bien, estos vínculos no siempre se presentan en los recorridos formativos. En la práctica son resueltos por los docentes de forma intuitiva y gracias a su predisposición para establecer dichos puentes.

Consideramos necesaria una reflexión acerca de los vínculos entre cultura visual y la cultura letrada para advertir aportes a la enseñanza, tanto en la formación de grado como en la capacitación docente y diseño de propuestas y materiales. En este trabajo nos planteamos como objetivo brindar una serie de orientaciones de contenido y metodología pensados a partir de las condiciones y posibilidades del trabajo docente (Viñao, 2002) en la enseñanza de la disciplina escolar específica.

\section{MARCO TEÓRICO}

Adoptamos una perspectiva didáctica etnográfica y circunstanciada. En el campo de la Didáctica de la Lengua y la Literatura (DLL), esta mirada ha sido delineada por los estudios de Cuesta (2012, 2019). Este enfoque nos permite sumergirnos en el cotidiano escolar e interactuar con factores tan constitutivos de la labor profesoral como la injerencia de las políticas educativas y el planteo de actividades áulicas o la relación con el saber disciplinar. Desde este enfoque, además, buscamos sistematizar principios para los profesores de Lengua, Arte (o disciplinas afines) sobre la base de prácticas históricas existentes (tanto las documentadas como las no documentadas hasta ahora $)^{2}$ en lugar de enunciar presuntas innovaciones o rupturas.

En el caso particular de la enseñanza de la Lengua y la Literatura como disciplina escolar en la actualidad, los vínculos con saberes acerca de la cultura visual forman parte del currículo solo de forma tangencial. Sin embargo, podemos advertir que en las prácticas efectivas, los elementos visuales son recurrentes. ${ }^{3}$ Señalar que vivimos inmersos en una cultura donde predomina la visualidad suena ya a verdad de Perogrullo; sin embargo, el análisis llevado a cabo por las didácticas específicas en torno a situaciones reales de enseñanza, currículo o materiales educativos muestra que ese consenso no necesariamente se ha traducido en una renovación de las prácticas que tienen lugar dentro de lo que Rockwell ha llamado "cultura escolar" (2009). Dussel (2009) constata el uso de elementos visuales en las aulas desde la génesis de la escuela argentina (en forma de láminas, gabinetes, mapas, libros, afiches, etc.) y en los escritos de pedagogos como Víctor Mercante; aun así, señala Dussel, no abunda hoy en día el uso crítico de los mismos sino que las propuestas e intervenciones observadas reeditan en su mayoría prácticas ya tradicionales de la escuela.

La necesidad de articular los conocimientos sobre la cultura visual con otras disciplinas escolares ya había sido advertida desde campos como el de la enseñanza de la Historia (Navarro Spinach, 2011) o en las propuestas recientes sobre el uso de memes de internet (Beltrán, 2016; Balda Álvarez, 2019; Chen y Ortiz, 2016; García Delgado, 2018) para enseñar contenidos de diversas áreas curriculares. Con el sintagma "articulación disciplinar" o "Trabajo interdisciplinario" nos referimos tanto a la vinculación de saberes de disciplinas diferentes llevadas a cabo por un mismo docente (por ejemplo, cuando se realiza alguna pro- 
ducción con el curso que requiere trascender la textualidad) como a las que realizan docentes de espacios curriculares de un mismo año por medio de acuerdos para el desarrollo de sus tareas (por ejemplo, bajo la forma de proyectos). La posibilidad que abre la articulación es la de producir aprendizajes significativos en los que se integren cuerpos de saber.

¿Por qué nos parece más oportuno pensar estos organizadores del trabajo docente a partir de la categoría "cultura visual" y no desde "arte"? En primer lugar, la cultura visual designa un objeto que rebasa los límites de la producción artística para abarcar los signos visuales en su conjunto (Hernández, 1996, 2010; Mejía Echeverri, 2009; Mitzoreff, 1999) y a una perspectiva que puede dar cuenta de los mismos. Esto supone pensar no solo en las imágenes canónicas del arte sino en otras manifestaciones que nos rodean cotidianamente, eliminando las distinciones entre "alta" y "baja" cultura e incorporando campos como el diseño gráfico o los estudios multimediales. En segundo, la categoría de cultura visual esta puede dialogar con disciplinas como el lenguaje visual (Acaso, 2006; Ciafardo, 2010), la semiótica, el análisis del discurso u otras afines que despliegan una mirada sobre los componentes y sus significados. Por último, al correr la mirada de lo artístico dejamos uno de los principales obstáculos que sesgan la mirada sobre la visualidad: la concepción de "creatividad". La idea romántica del genio creador en el campo de las artes (y podemos tomar la escritura literaria como parte de ellas) suele neutralizar tanto la producción de obras (pues estas serán creativas si el productor tiene "el don") y por exclusión condena la enseñanza de lo visual al mero ejercicio de aplicación o al reconocimiento de recursos de una supuesta gramática visual. ${ }^{4}$

Existe una preocupación en los estudios sobre la cultura visual que se puede vincular con los objetivos de la DLL. Nos referimos a la meta de generar en el alumno la capacidad para desmontar los sentidos (históricos, ideológicos, estéticos) de los mensajes. En el caso de los estudios de cultura visual, la principal manifestación de esta inquietud es el problema de la transparencia de la imagen que se advierte en especial cuando se enfoca el curriculum en la percepción (Hernández, 1996, p. 14). Según comentan varios autores, existe una creencia muy arraigada acerca de la imagen visual como un signo de fácil decodificación gracias a la inmediatez icónica que la caracteriza (es decir, gracias a la semejanza con el referente). ${ }^{5}$ Como la imagen sería sencilla de interpretar, los esfuerzos del sistema educativo estuvieron más concentrados en la cultura letrada, considerada más compleja por su abstracción. Dussel (2009) agrega que en el campo educativo se manifestó una sospecha constante sobre la imagen visual a partir de ideas presentes en el pensamiento de Platón. La visión, entonces, no es algo universal y neutro sino algo que se aprende (Dussel, 2009). En una conferencia (Dussel, 2012) sobre el rol de los medios digitales en la educación, Dussel vuelve sobre estos problemas y registra la presencia de la concepción transparentista acerca de la imagen y de los medios digitales: no habría en ellos nada que enseñar desde las diferentes materias escolares; sólo habría que hacer uso de los mismos.

La perspectiva de la cultura visual como desmantelamiento de los sobreentendidos culturales, funciones ideológicas y políticas de las formas visuales (Mejía Echeverri, 2009, p. 43) converge con un propósito de la DLL: educar en cuanto a las formas de observar y analizar las expresiones culturales en su producción de sentido así como producir otras nuevas. Esos sentidos analizados, al igual que las formas que los vehiculan se enmarcan en el discurso social (Angenot. 2010), sistema que los regula. La atención a este sistema nos permite dotar de significación las unidades que utilizamos para la enseñanza en lugar del tradicional énfasis en el formalismo y las categorías desgajadas del uso.

\section{Estado de LA CUESTión}

Trazaremos aquí un breve recorrido histórico sobre las relaciones entre cultura visual y letrada para la enseñanza escolar. 


\subsection{La historia curricular}

Los primeros aportes que vinculan la imagen visual con la enseñanza y aprendizaje de otros contenidos (como la lengua, la biología o la geografía) se remontan al tratado Orbis sensualium pictus (1658), de Comenius. Esta obra fue específicamente pensada para renovar la enseñanza del latín (Aguirre Lora, 2001, p. 5) y tuvo influencia en la práctica educativa de la modernidad. Se puede localizar esa influencia, por ejemplo, en los catecismos y cartillas alfabetizadoras del período colonial con sus métodos de asociación imagen-palabra, entre otras propuestas.

Situados ya en el sistema escolar de los estados modernos, el uso de elementos visuales icónicos en la educación tuvo injerencia sobre todo en las Ciencias Naturales (por medio del dibujo utilizado a modo de registro) y en la Historia (Dussel, 2009). No se registra una vinculación explícita con la enseñanza de la lengua o idioma nacional. La educación formal en Argentina nació en el marco del proyecto modernizador liberal y se consolidó bajo el paradigma de la escuela normal a fines del siglo XIX. En ese contexto, la enseñanza lingüística se encauzó hacia otras finalidades. López García (2015) señala que el papel de la educación desde ese momento hasta la década de 1930 estuvo marcado por la búsqueda de homogeneización idiomática. De este modo, los contenidos del espacio curricular llamado Idioma Nacional o Castellano ${ }^{6}$ se encontraban regulados por un conjunto de políticas y un cuerpo de saberes sobre la lengua. Estos se traducían en producciones como libros de texto y gramáticas escolares (que en dicho período incluía desde las "partes de la oración" hasta la ortografía, dicción y elocución). ${ }^{7}$ La definición de gramática de esta época era "arte de hablar y escribir correctamente el idioma", una definición de carácter prescriptivo que se extendió mucho más allá del normalismo y de ese momento histórico.

Los contenidos prescriptos se encontraban concentrados en el trabajo sobre la corrección de los llamados "vicios" asociados a los dialectos regionales y a las lenguas de inmigración como se desprende del análisis de documentos oficiales y materiales didácticos (López García, 2015). La producción dentro de estos espacios curriculares quedaba limitada a la composición a partir de un tema asignado y bajo la imitación de modelos localizados en un canon literario y a su posterior ilustración por medio de dibujos. Lejos estaba la posibilidad de pensar el contacto y aprovechamiento didáctico de vínculos posibles entre Lengua y la Literatura y otras disciplinas (que aún no se habían constituido como tales) como el Lenguaje Visual. El aspecto más próximo a la dimensión visual radicaba en la caligrafía de los alumnos sometida a evaluaciones acerca de la pulcritud y claridad que, además, se tomaban como indicador objetivo de las condiciones morales e intelectuales de los escribientes. Por otro lado, el uso de la ilustración se limitaba a tareas en que los estudiantes dibujaban escenas de fragmentos literarios leídos, es decir, a una operación de traducción donde se concebía la imagen como sucedáneo del texto. En cuanto a la enseñanza de lo que hoy llamamos cultura visual se concentraba en el espacio de Arte y reducida al canon de obras artísticas, la Historia del Arte y a la ejercitación. Señala al respecto Cozzi:

El arte es visto aquí como complemento del conocimiento -entendido como unívoco y universal- y por lo tanto es reductible a la esfera de lo sensible, opuesta a lo inteligible. La copia, la imitación y la reproducción de modelos secuenciados de manera acumulativa constituyen las estrategias pedagógicas por excelencia para la adquisición de saberes y destrezas (2017, p. 7).

Un segundo momento destacable en este recorrido tiene lugar a partir de la década de 1930, con el auge de propuestas alternativas frente a la pedagogía normalista de base positivista. Nos referimos a las experiencias escolanovistas basadas en los aportes de Montessori, Claparéde, Dewey, Freinet, Décroly y otros pedagogos que propusieron una enseñanza puericéntrica basada en la experimentación y expresión de la creatividad (Belardinelli y Catibiela, 2017; Davini, 2008). Se destaca en este momento histórico la propuesta de las hermanas Olga y Leticia Cossettini, representantes locales del escolanovismo local. Su contribución se recoge en los libros Escuela serena, un ensayo sobre los principios de su pedagogía, y El niño y su expresión, un análisis de experiencias que recoge trabajos como dibujos, poemas y otras composiciones de alumnos que formaron 
parte de una exposición previa. La propuesta de ambas pedagogas ponía el acento en la expresión estética como vehículo para el logro de aprendizajes. Señalan Goldar y Spolidoro:

En esta línea, describieron la función de los cuadernos escolares de los niños en los que la imagen aparecía como productora de subjetividad a diferencia de lo que ocurría con los cuadernos de clase de la escuela tradicional, los cuales operaban como dispositivos de normalización, reduciendo a la imagen solo como ilustración de la palabra (2016, p. 2).

Vemos aquí una vinculación entre la dimensión visual, la lengua y la literatura donde localizamos el ingreso de términos clave a la reflexión pedagógico-didáctica: la creatividad y la expresividad. La escuela de las hermanas Cossettini supuso un hito donde se vinculan por primera vez las disciplinas de las cuales venimos hablando, aunque no se ponía el acento en el análisis de unidades constitutivas de literatura, lengua o cultura visual sino en la expresión creativa (Belardinelli y Catibiela, 2017). Esta idea será privilegiada por en el sistema educativo para la producción artística durante décadas. ${ }^{8}$

La experiencia escolanovista referida fue más bien un caso excepcional y periférico dentro del sistema educativo. Hacia la década de 1960, la enseñanza de la Lengua y la Literatura recibió la influencia del estructuralismo lingüístico y literario (Cuesta, 2012; Massarella, 2017). Esta corriente produjo una renovación en el cuerpo de saberes con el fin de "cientifizar" la enseñanza de ambos objetos; se aminoró la dimensión normativa en el trabajo de la lengua y potenció la descripción y clasificación de unidades verbales pero, a la vez, se produjo una mayor concentración en las estructuras formales que en los significados. En cuanto al trabajo interdisciplinario con espacios curriculares dedicados a la cultura visual, podemos observar que muchas propuestas editoriales de la época respondieron a las nuevas tendencias y recurrieron a consignas de ilustración de lo escrito o leído, es decir, de forma complementaria y desprovistas de reflexión sistemática. Los lineamientos curriculares de la época no se pronunciaron al respecto sino que se limitaron a señalar la necesidad de fomentar la apreciación estética en relación con la literatura (Massarela, 2017).

En algunas de las experiencias mencionadas hasta ahora (y parcialmente en las que seguirán) se concibe la literatura como forma de escritura creativa cuya práctica estaría reservada a escritores profesionales (depositarios de la inspiración) antes que a los estudiantes; la literatura es vista como expresión autoral y uso estético del lenguaje. No obstante, encontramos propuestas como la Didáctica de la lectura creadora, de María Hortensia Lacau donde se integran ejercicios de escritura literaria como modo de reflexión en torno a la literatura (Massarella, 2017). Posteriores experiencias como la del Grupo Grafein y el concepto de escritura de invención (Alvarado, 2003) serían absorbidas por la escuela, lo cual desplazó la escritura de ficción del mero carácter de ejercicio y permitió que la misma sirviera como práctica reflexiva. De un modo similar, el ingreso se la producción de artes visuales a la curricula escolar estaría marcado por una orientación similar (Belardinelli y Catibiela, 2017), buscando desplazar las concepciones románticas acerca de la creatividad.

El cuarto momento que referiremos se da con la reforma educativa propiciada por la Ley Federal de Educación 24.195 (1993). Esta legislación reorganizó el currículum en los Contenidos Básicos Comunes ( $\mathrm{CBC})$ que en materia de Lengua y Literatura oficializan el ingreso del cuerpo de saberes que ha sido denominado enfoque comunicativo: semiótica, pragmática, sociolingüística, análisis del discurso, lingüística textual. El trabajo con la lengua pasó de privilegiar la unidad oracional al discurso y a la legitimación del trabajo con géneros como los periodísticos bajo la propuesta de abordar los usos de la lengua a partir de la cotidianeidad del alumno. Con los $\mathrm{CBC}$ ingresan de forma sistemática y con un aparato conceptual dimensiones como la paratextualidad y la preocupación por algunos elementos constitutivos de los soportes de la literatura y otras formas comunicativas verbales. ${ }^{9}$ Sin embargo, como señala Dussel (2009), la práctica se condijo poco con esa anunciada renovación. Si bien ingresaron los medios de comunicación como materia de reflexión a las aulas, su análisis se produjo principalmente en términos lingüísticos e ignorando prácticamente los componentes multimodales o reduciéndoles a categorías familiares de las ciencias del lenguaje. 


\subsection{Los lineamientos curriculares en la última reforma educativa}

La continuidad e influencia de los CBC queda plasmada en los Núcleos de Aprendizaje Prioritarios (NAP) que acompañaron a la Ley de Educación Nacional 26.206 (2006). A continuación analizaremos con mayor detenimiento este marco de política curricular.

El trabajo prescripto (es decir, aquel que se figura en documentos de políticas educativas) para el docente queda trazado por los NAP. Si examinamos el documento producido para Lengua y Literatura observaremos algunos puntos de vinculación con la cultura visual. En relación con la paratextualidad se menciona periféricamente que uno de los objetivos consiste en:

[...] poner en juego estrategias de lectura adecuadas al género del texto y al propósito de lectura: consultar elementos del paratexto, reconocer la intencionalidad, relacionar la información de texto con sus conocimientos, realizar -cuando sea pertinente- anticipaciones, detectar la información relevante, realizar inferencias, establecer relaciones entre el texto, las ilustraciones y/o los esquemas que puedan acompañarlo; relacionar el texto con el contexto de producción (ME, 2006a, p. 21).

Nuevamente, este concepto aparece ligado a la organización informacional pero no se sugiere específicamente que se reflexione en torno a los rasgos visuales de los paratextos y sus construcciones de sentido. Parece subyacer la concepción transparentista de la imagen visual cuando se coloca a la ilustración como un signo más que puede proveer información (¿objetiva?) aunque esta también es producto de una selección y montaje tanto como lo es el texto verbal.

Por otro lado, los NAP orientados al ciclo superior de la secundaria proponen pensar la relación entre la literatura y otras expresiones artísticas, siempre en términos de relaciones intertextuales (adaptación, parodia, referencia, etc.):

Establecer conexiones entre obras de diferentes géneros literarios y con el cine o con la televisión para introducir el concepto de intertextualidad y acrecentar las posibilidades de interpretación (ME, 2006b, p. 36).

Esto también aparece indicado como objetivo para el espacio de Arte bajo la idea de trabajo comparativo entre las artes visuales y otros lenguajes (ME, 2006c).

Por último, los NAP introducen la escritura de literatura, una incorporación que retoma aportes de la modalidad tallerística: "Escribir textos narrativos y poéticos a partir de consignas que propicien la invención y la experimentación, valorando la originalidad y la diversidad de respuestas para una misma propuesta" (2006b, p. 26). Notamos la pervivencia de la noción de creatividad (ligada a la originalidad) ya advertida dentro de esta incorporación. Se señala también como contenido la edición de las producciones teniendo en cuenta aspectos del diseño para publicación (2006b, p. 19).

Cuando pasamos a la adaptación de los NAP en los diseños curriculares de las provincias ${ }^{10}$ (en el caso que tomaremos, el diseño de la provincia de Buenos Aires), la incorporación de la escritura literaria es la primera en brillar por su ausencia. El diseño del espacio curricular Prácticas del Lenguaje (DGCyE, 2008) se refiere por escritura a la de textos de estudio, crítica y análisis en torno a la literatura pero no a la escritura de ficción. También propone el comparatismo, nuevamente ligado a la literatura y la intertextualidad (DGCyE, 2008, p. 389) y sin precisar posibles vinculaciones por medio de categorías concretas como las que aporta el Lenguaje Visual. Se sugieren algunas prácticas a modo de orientación metodológica pero sin orientaciones sobre conceptos vinculantes como se observa en el diseño de Literatura para $4^{\circ}$ año: "[... sacar y recopilar fotos que se vinculen a un texto poético, dibujar, musicalizar poemas, crear un video a partir de un texto leído, crear una historieta a partir de un cuento, etcétera" (DGCyE, 2010, p. 16). Parece que la creación de una foto o dibujo no entrañara consideraciones sobre los modos de representación sino que fueran la mera ilustración del referente literario sin mayores complejidades ni para el alumno que debe realizar la tarea ni para el docente que debe supervisarla y orientarla. 
De este modo, gran parte de las articulaciones latentes en el diseño curricular de Provincia de Buenos Aires queda ligada al trabajo con la literatura y a partir de la comparación de producciones ya existentes. El estudiante queda prácticamente ajeno a la producción cultural (visual o verbal) y es puesto en el lugar de interpretarte de la misma. Estas orientaciones curriculares no suponen un avance que permita dar cuenta de una formación en las literacidades cambiantes y multifacéticas de la actualidad a la vez que atomizan contenidos cada vez que la limitan a la comparación entre lenguajes.

Una última observación sobre los lineamientos para Lengua y literatura como para Arte es la enfática mención del desarrollo de competencias como objetivo de cambios espacios (competencias lectoras y productoras de texto en un caso, competencias para la producción y comprensión de la visualidad en el otro). Esta tendencia curricular internacional data de por lo menos mediados de la década de 1980 según señala Díaz Barriga (2005) y se condice con la influencia de organismos internacionales que han marcado las políticas educativas de estas últimas décadas.

\section{Metodología y CRITERios de SELEccióN}

A partir del trazado de un estado del arte de acuerdo con la currícula y antecedentes históricos, definimos criterios para la postulación de los organizadores didácticos.

Partimos de un cotejo de diferentes experiencias de enseñanza registradas a modo de observación empírica. Esto nos permite registrar prácticas en la escuela secundaria a partir de las posibilidades materiales de realización y del sentido que con ellas se produce. Se trata de una aproximación cualitativa (Baptista, Fernández y Hernández, 2006) e inferencial. Tomamos como antecedente los trabajos de investigación de DLL de González y Arias (2014), González (2016) y Gagliardi (2020) que adoptan un diseño metodológico comparativo a partir de la indagación sistemática y sistematizada.

Luego de la observación paramos a realizar inferencias sobre las regularidades observadas, las sistematizamos y analizamos. A partir de eso organizamos la propuesta teniendo en cuenta factores como las tradiciones de formación docente que muestran la pervivencia de la separación entre "Literatura" y "Arte" circunscribiendo el segundo término parcialmente dentro del campo de la cultura visual y el primero a una forma artística más ligada a la tradición humanista letrada. Esta separación organiza la formación docente en carreras diferenciadas y también suele traducirse en escasos espacios para poner en diálogo las disciplinas. Por este motivo, la mayor parte de los organizadores seleccionados se refieren a conceptos que ya forman parte de las trayectorias formativas y sus tradiciones. Pensamos también en la posibilidad de que sirvan como referencia tanto para docentes de Lengua y Literatura como de Arte(s) en sus respectivas clases como para trabajos realizados en conjuntos cuando existe la posibilidad de realizar acuerdos entre colegas dentro de una institución.

Los ejes organizadores propuestos se nombran a partir de categorías que, en algunos casos, son originalmente de índole formal; sin embargo, en virtud de que los postulamos a partir de la observación de prácticas reales, estas categorías se encuentran mediatizadas por el proceso de transposición didáctica y enfocados para habilitar la dimensión semántica. De este modo, los saberes del Lenguaje Visual, la Semiótica o Narratología se piensan en función de la construcción de sentidos y la forma en que se refuerzan mutuamente para la creación de mensajes multimodales. El aporte de Angenot (2010) sustenta esta integración: para el investigador, el "discurso social" es un sistema que regula la producción de sentido de "todo lo decible e imprimible" (p. 22); esas regulaciones, frecuentemente se pueden advertir en regularidades, lugares comunes que comparten sistemas de signos diferentes pero organizados a partir de una misma hegemonía. Dado que el discurso social sólo puede ser estudiado en función de un corte sincrónico, Angenot nos abre la posibilidad de ver que las construcciones de sentido son históricas y variables. Al pensar la discursividad social actual podremos definir organizadores que nos parezcan relevantes para pensar la articulación interdisciplinaria. 
Por último, estos ejes organizadores han sido pensados para la tarea docente, lo cual implica que el profesor tome decisiones sobre cuáles de los contenidos serán trabajados de forma explícita (construyendo, por ejemplo, saberes declarativos) y cuáles serán implícitos, así como problematizar los límites entre los mismos y los ligeros solapamientos entre categorías.

\section{Propuesta}

\subsection{Denotación y connotación}

Este par conceptual se encuentra presente en manuales escolares desde hace décadas. No obstante, su abordaje dentro de Lengua y Literatura ha quedado fosilizado o sujeto a un tratamiento limitado a determinados objetos específicos. Una inspección de manuales escolares para secundaria muestra que el par denotación/ connotación aparece en unidades de trabajo centradas en la poesía, descartando así su relación con otros géneros literarios o con mensajes publicitarios por ejemplo; es decir, un caso de atomización de contenidos.

La connotación queda desprovista de la dimensión ideológica que vieron en ella los trabajos clásicos de Barthes (1970) y Kerbrat Orecchioni (1983). Desde el punto de vista del lenguaje visual, sabemos que la imagen siempre tendrá connotaciones que pueden ser localizables en algún elemento del mensaje construido; la lengua, tampoco está exenta de esta posibilidad pues nunca es neutra. Sin embargo, formulaciones de los manuales escolares reproducen definiciones difíciles de sostener desde el punto de vista teórico como "lenguaje denotativo" vs "lenguaje connotativo", donde pareciera reeditarse la oposición clásica del formalismo ruso entre legua poética y lengua cotidiana. Por otro lado, el par connotación/denotación concibe la connotación como el dominio de la subjetividad individual y deshistorizada. Kerbrat-Orecchioni y Barthes no hacen más que demostrar que muchos de los significantes de connotación producen en su mayoría asociaciones sobre la base de estereotipos, es decir, de convenciones o significados de connotación más o menos estables. Volviendo a Angenot, las convenciones cifradas en connotaciones relativamente estables responden a hegemonías presentes en un corte sincrónico de discurso social.

Dentro de las categorías del lenguaje visual que pueden constituirse como significantes de connotación destacamos el color, el trazo, iluminación, encuadre, disposición de elementos, es decir, la morfosintaxis de la imagen y la dimensión semántica que ayuda a construir; podemos sumar la morfosintaxis tipográfica que también responde a parámetros del lenguaje visual. Dentro de la lengua, podemos señalar los recursos fóni$\cos$ (rimas, aliteraciones, pausas), la selección léxica, la ubicación de las palabras en la frase, entre otras.

Analizaremos unas experiencias didácticas donde este principio resulta útil para pensar la tarea realizada. En la imagen 1 vemos una muestra de los textos producidos por un curso de $3^{\circ}$ año en la EES No 46 (La Plata). La consigna, a partir de un texto leído, pedía crear un bestiario con criaturas inventadas por cada alumno, luego de la escritura y revisión de la misma se pensó en exponer los trabajos por medio de una muestra en las paredes del pasillo de la escuela y luego se recogió en una antología (VVAA, 2015). Aquí se tomaron decisiones para montar el dispositivo donde la connotación emerge: se buscó unificar por medio de una tipografía y un color los trabajos (Gagliardi, 2017); el debate con el curso sugirió que el color dominante más apropiado era el verde "por su relación con la naturaleza", es decir, un significado de connotación muy difundido. Los alumnos, además, sugirieron incorporar al diseño de cada soporte para los textos arañazos, cortes irregulares para aludir a la ferocidad de algunos de los animales que habían pensado desde el texto y la ilustración, en un claro refuerzo semántico del contenido verbal. 


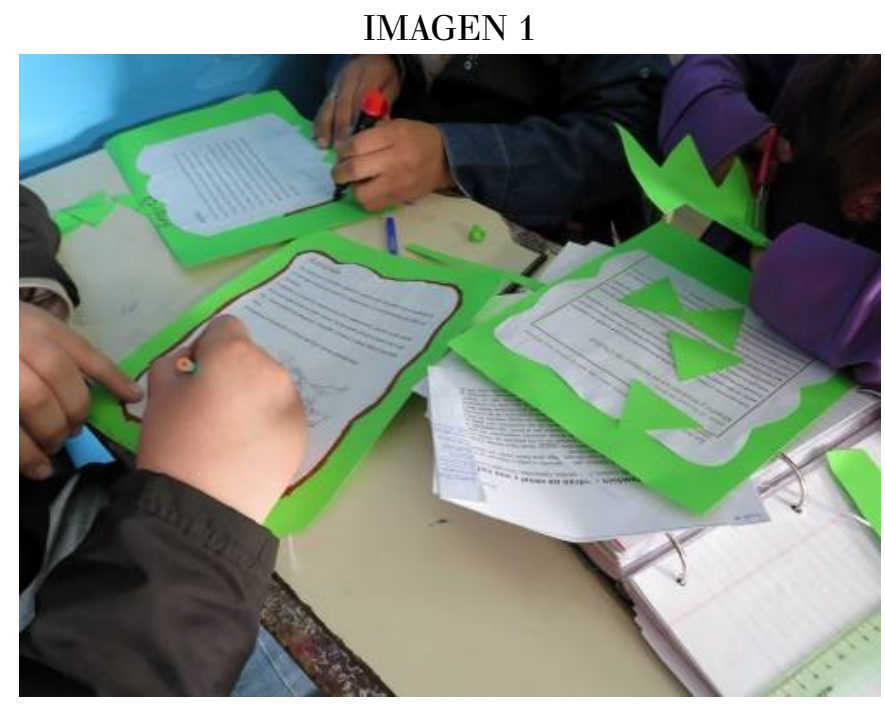

Fuente: elaboración propia.

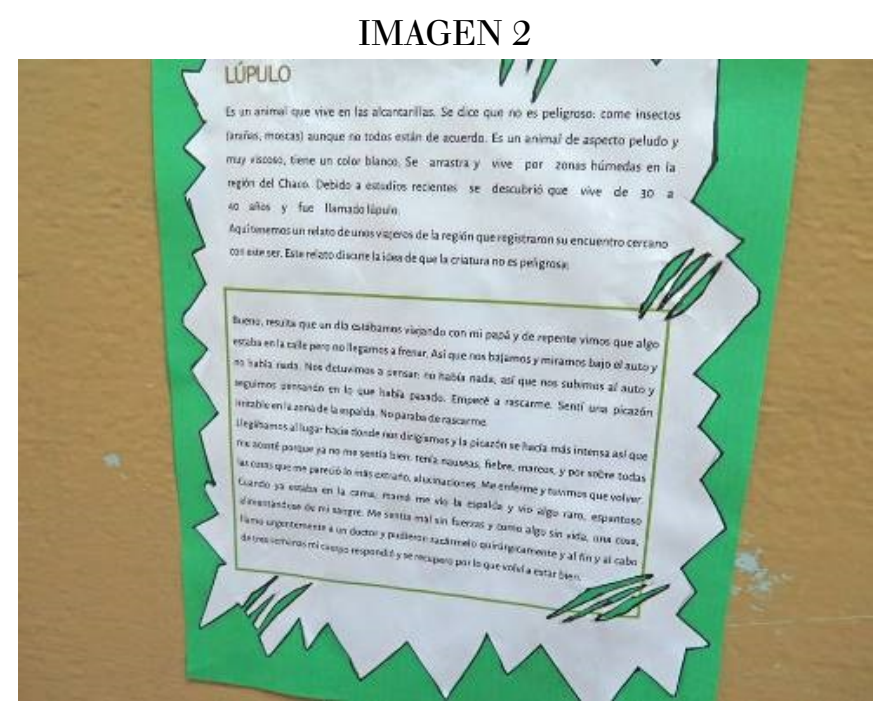

Fuente: elaboración propia.

Por último, en un curso de $4^{\circ}$ año (EES No 31 ), se produjo un periódico basado en relatos mitológicos griegos, ya analizado en Gagliardi (2016). Para construir el verosímil paródico del trabajo, se reflexionó con el curso sobre el lenguaje visual a adoptar. Se seleccionó una paleta basada en el negro y naranja y la representación planimétrica más una familia tipográfaca de época para connotar la "grieguedad", es decir, una supuesta identidad griega estereotipada y reconocible a partir de las cerámicas arcaicas de modo similar a la italianidad que Barthes localiza en publicidades. Vemos que aquí, la reflexión en torno a la connotación visual busca reforzar el verosímil.

Cuesta (2012, p. 246-247) analiza un caso en que la docente propone escribir retratos a partir de imágenes publicitarias. El uso de las selecciones léxicas que se debate entre alumnos y docente ("pelo limpio", "cabello brillante", "suave y terso") pone en colisión estilística las connotaciones de la actividad (el retrato poético, un género tradicional de la primera mitad del siglo XX) y el referente de la publicidad. La experiencia demuestra, sin el tratamiento explícito de la categoría connotación, que las orientaciones de significado constituyen parte importante del quehacer lingüístico en el aula. Lejos de ser transparente, el lenguaje requiere trabajo a partir de las inscripciones de los significantes en la discursividad y en sus negociaciones de sentido (prestigio, representaciones culturales, aparente adaptación a lo que se espera en la escuela, etc.). 


\subsection{Estereotipia}

El concepto de estereotipia ha sido analizado en términos de representación social, cognitiva y artística (Amossy y Herschberg Pierrot, 2001). En el campo de las artes constituye un contenido de reflexión para identificar lo conocido (el preconcepto) y posibles tomas de distancia en la práctica, así como para reconocer configuraciones estables en el discurso (ME, 2006c, p. 16). En el campo de la lengua y la literatura ha servido para identificar tanto la construcción de personajes en la literatura como las ideas y frases hechas (o clichés) en los discursos.

En otra actividad (Imagen 3) realizada con un $4^{\circ}$ año en el espacio de Literatura (EES No 31, La Plata), se analizó la figura del héroe en literatura y otras producciones culturales (Gagliardi, 2016, 2017). Se pidió a los alumnos que de forma colaborativa agruparan los personajes de las imágenes en categorías (héroe clásico, antihéroe, héroe cotidiano, superhéroe) y explicitaran los criterios que utilizaron. Surgieron interesantes reflexiones donde se vislumbra lo que se concibe habitualmente como héroe y por qué, cuáles personajes se apartan de esas representaciones estereotipadas, qué ocurre con las representaciones de las identidades de género. Localizaron regularidades como la musculatura, los valores asociados al cuerpo femenino, la representación de la identidad de género en el caso de los personajes del manga y animé y los valores asociados al heroísmo. En cada uno de los signos visuales, los alumnos asociaban valores sobre la base de su experiencia cultural pudiendo incluso cuestionar la falta de la denominación "heroína" y sus variantes en la clasificación. Luego, a partir de lo examinado en imágenes, se realizó un trabajo descriptivo en torno a las figuras heroicas de Martín Fierro, Odiseo y otros personajes de los textos leídos.

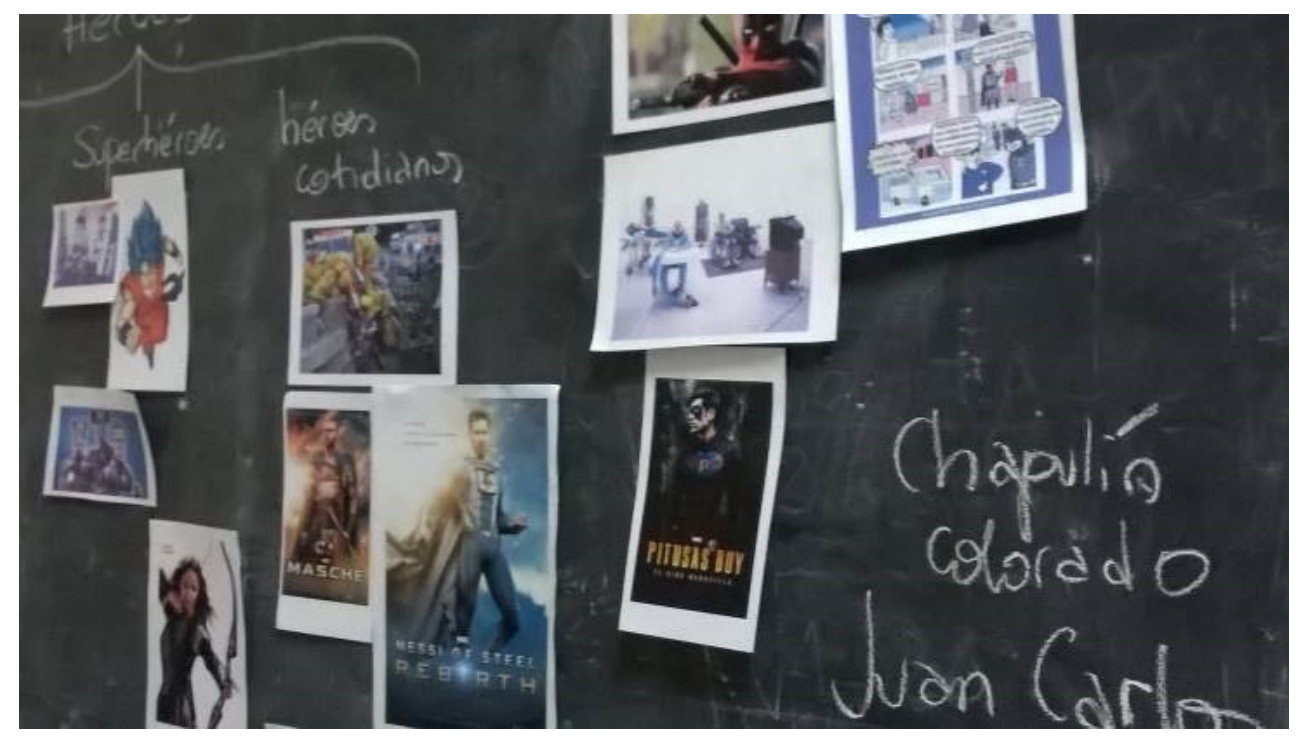

Fuente: elaboración propia.

\subsection{Intertextualidad y parentesco cultural}

Uno de los ejes más productivos consiste en trabajar el conjunto de referencias y reenvíos que se hacen desde un mensaje a otros, ya sea desde texto a imágenes, películas o viceversa. Por un lado, esto se apoya en las observaciones acerca de la presencia de consumos culturales en los modos en que los alumnos ingresan a la lectura literaria (Cuesta, 2006, 2012, 2019). Por el otro, en las recomendaciones curriculares que hemos mencionado donde constituye un contenido puntual.

Tanto los conceptos de intertextualidad como los de transtextualidad en la lengua pueden emparentarse con otros de la cultura visual. Anguio (2018, p.139-140) propone la idea de parentesco cultural para designar 
"las más auténticas preferencias musicales, cinematográficas, literarias, televisivas y de intereses en general" del estudiante con los cuales puede vincular sus producciones y otras que analice. Parodias, adaptaciones, remixes, mashups y otras formas dialógicas conforman este universo de referencias.

Tomamos una experiencia realizada con un curso de 6to año (EES San Benjamín, Los Hornos). Los estudiantes debían analizar una serie de imágenes que contenían parodias, el concepto que se estaba trabajando. En la interacción las mismas debían establecer continuidades con los recursos que habíamos estado trabajando en la unidad sobre literatura y humor (hipérbole, ironía, uso de la polisemia, anacronismo, etc.).

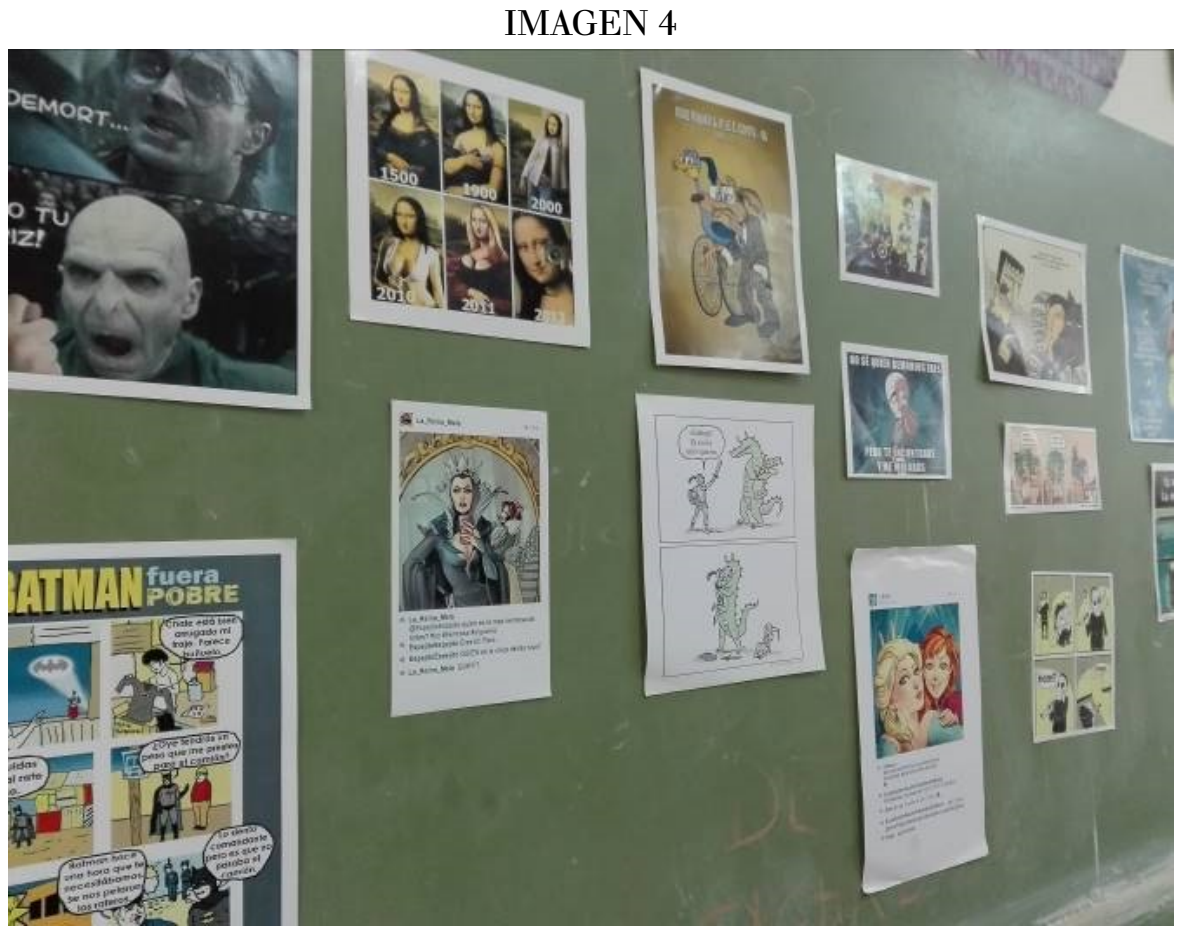

Fuente: Gagliardi (2017)

Un obstáculo que presentaba la actividad (y que a la vez servía como criterio de selección para las imágenes que desearan trabajar) era que debían conocer el referente al que se aludía para poder realizar el análisis, es decir, conocer la clave que permitía interpretar la relación entre fuente y reformulación.

La parodia como procedimiento discursivo se encuentra muy arraigada en la cultura así como en muchos de los consumos y prácticas de los estudiantes por fuera de la escuela. Constituye una parte importante de ciertos mensajes como los memes de internet; las experiencias de apropiación de los memes con fines pedagógicos frecuentemente resaltan la importancia de atender a la ironía y la parodia para la construcción de estos mensajes (Beltrán, 2016; Chen y Ortiz, 2016; García Delgado, 2018). En este sentido, investigaciones recientes de la DLL (Cuesta, 2019; López Corral y Moya, 2017) entienden la inscripción de la literatura en el entrevero del discurso social y los consumos culturales de los jóvenes: géneros, procedimientos y temáticas que habitualmente se enseñanza como prerrogativa de la literatura encuentran su continuidad en otras prácticas que ejercen los estudiantes.

\subsection{Paratextualidad}

Los paratextos constituyen el entorno del mensaje verbal; nos proporcionan señalizaciones, clave para la lectura y se encuentran estrechamente vinculados a la connotación en el caso de las imágenes, ilustraciones 
y puesta en página (Alvarado, 1995). Es tradicional de la formación en Lengua y Literatura que el entorno visual de las producciones verbales apenas sea tenido en cuenta; se suele privilegiar en análisis del elemento verbal como si la palabra se presentara en la página desprovista de representación gráfica (salvo en géneros específicos como el caligrama). Recientemente con el impacto de la Semiótica y la Historia del Libro y la Lectura comienzo a pensarse la edición del texto como una dimensión pertinente para la reflexión sistemática en la formación docente. Su rol en la construcción de un verosímil literario puede resultar un objeto de reflexión útil para proyectos de escritura así como para el acompañamiento textual de proyectos visuales (textos descriptivos de obras, títulos).

En relación con este organizador didáctico volvemos a la mencionada experiencia llevada a cabo con un curso de $4^{\circ}$ año. En el marco de una secuencia de trabajo con la cosmovisión mítica (DGCyE, 2008), la construcción del periódico sobre mitología implicó considerar la organización visual de la información para reforzar, por ejemplo, el trabajo en torno al sensacionalismo como estrategia periodística con el que se pensaron los títulos. Los registros del proceso creativo (imágenes 3 y 4) muestran una serie de cambios donde la paratextualidad forma parte del sostenimiento del verosímil necesario para construir la parodia. De casos como el inicial, donde el pautado de la página, las elecciones tipográficas y el color no se asemejaban al prototipo de publicación periódica, las reflexiones y decisiones tomadas con el grupo permitieron asemejar las producciones al formato de un periódico. Se seleccionaron una paleta basada en el negro y naranja (como en las cerámicas arcaicas) y la representación planimétrica más una tipografía de época para connotar "grieguedad", es decir, una supuesta identidad estereotipada; todo esto se suman al uso de expresiones formulísticas del discurso periodístico ("polémicas declaraciones", "Se cree que..."), el proceso de trabajo se revela orientado a clarificar la estrategia paródica de los textos. En el mismo proyecto se incluyeron en un gesto anacrónico formas de comunicación de gran impronta visual como los tweets de los dioses del panteón helénico. ${ }^{11}$

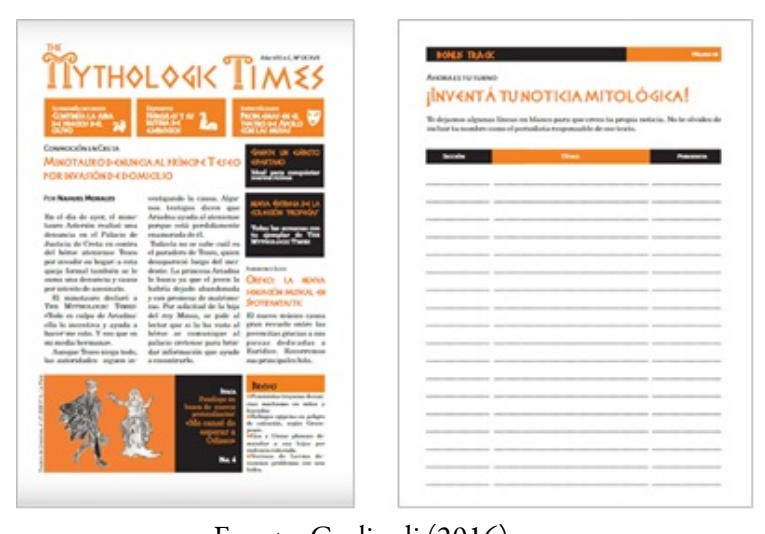

Fuente: Gagliardi (2016)

Las posibilidades de la paratextualidad para orientar el ingreso a los textos o para cifrar aspectos de los mismos pueden ser abordadas también desde las partes del libro. Por ejemplo, en una secuencia didáctica de lectura de Cuentos de amor de locura y de muerte, de Horacio Quiroga registrada en un $2^{\circ}$ año (EES No 36) se trabajó con las tapas de diferentes ediciones del libro: unas recurrían al dibujo de personajes, otras a fotografías que enfatizaban el clima y evitaban la personificación. Luego de la lectura de varios de los cuentos, los estudiantes debían comparar la forma en que los mismos eran representados por los paratextos icónicos. Esto debía fundamentarse por escrito, para lo cual era necesario explicitar la relación entre el modo de representación elegido, estilo y lo que los textos literarios transmitían, así como la clave de lectura que el título del volumen brindaba para orientar la lectura dentro de una ambientación y continuidad temática. 


\subsection{Enunciación y estrategias retóricas}

Considerar la escritura, lectura y producción visual más allá de sus propiedades formales nos lleva a dar cuenta de las estrategias retóricas que influyen en la producción de sentido. La retórica ha sido abordada con frecuencia a modo de inventario de figuras o topoi que el alumno debía reconocer (generalmente, dentro de géneros como la poesía, otro caso de atomización). Los aportes del Lenguaje Visual permiten reflexionar sobre esta dimensión (así como sobre la enunciación) que, hasta las últimas décadas, quedaba más ligada al trabajo con la materia verbal.

Los saberes del orden de la lengua y la literatura implicados pueden ser las nociones de narrador, enunciador y focalización, es decir, las voces en el texto y sus operaciones; en el caso del lenguaje visual, las nociones de punto de vista, plano, encuadre representan la enunciación en la imagen. En cuanto a la retórica, las figuras como la hipérbole, comparación, metáfora y sinécdoque resultan las más frecuentes para ambas disciplinas. Podemos observar el uso de las figuras dentro de estrategias discursivas como la parodia que articulan los topoi y la enunciación en el marco de un objetivo para, así, rehuir del mero reconocimiento formal de recursos.

Como experiencias didácticas podemos referir actividades de escritura de invención (Alvarado, 2003) a partir de imágenes compuestas en Arte o brindadas por el docente. En algunos de estos trabajos podemos localizar, según el caso, o la exageración de rasgos que producen una representación grotesca pueden pensarse en términos de figuras como la hipérbole y construcciones como el absurdo que también pueden rastrearse en los textos producidos por los estudiantes. ${ }^{12}$

La enseñanza de la escritura literaria en la escuela, dijimos, queda ligada a estrategias del docente que incorpora la modalidad de taller. Esta modalidad implica producir y reflexionar a partir de la producción, de un modo afín a cómo puede lograrse en espacios como Arte; en este sentido resulta beneficiosa tanto para la escritura de textos literarios como no literarios. Las figuras retóricas pueden pensarse como estrategias para la construcción de descripciones y explicaciones. Ejercicios habituales para fomentar la escritura como la redacción descripciones donde se pida elidir el nombre de lo que se está describiendo permiten, en tanto juego de la inventio retórica, enfocar aspectos y jugar con sinécdoques y comparaciones. Estos procedimientos pueden pensarse como formas de mantener el suspenso en géneros diversos, generar efectos de incertidumbre o sorpresa.

La enunciación puede pensarse a partir de la comparación entre la figura del narrador como fuente informativa en la literatura, el enunciador en textos no literarios y la cámara o espacio plástico en el caso de dibujos, pinturas y videos según el caso. El texto resulta un espacio bidimensional que, como una fotografía, no posee la tercera dimensión que habilite la posibilidad de recorrer y buscar nuevos ángulos como sí lo hacen las instalaciones o la escultura; el lector-espectador está condicionado parcialmente por un dispositivo que media su relación con la obra artística. Desmontar las estrategias enunciativas que construyen el dispositivo permite un análisis del artificio y reflexionar sobre la no transparencia de los mensajes. Mattioli (2012) analiza una propuesta para el trabajo de la focalización narrativa a partir de fotografías y del trabajo sobre la mirada. Este uso analógico de la imagen parte precisamente de los elementos compositivos que hemos mencionado así como desde los presupuestos culturales de los alumnos.

Por otro lado, mencionamos una actividad, llevada a cabo con un $3^{\circ}$ año en torno al concepto de narrador literario se trabajó también de forma comparativa. 


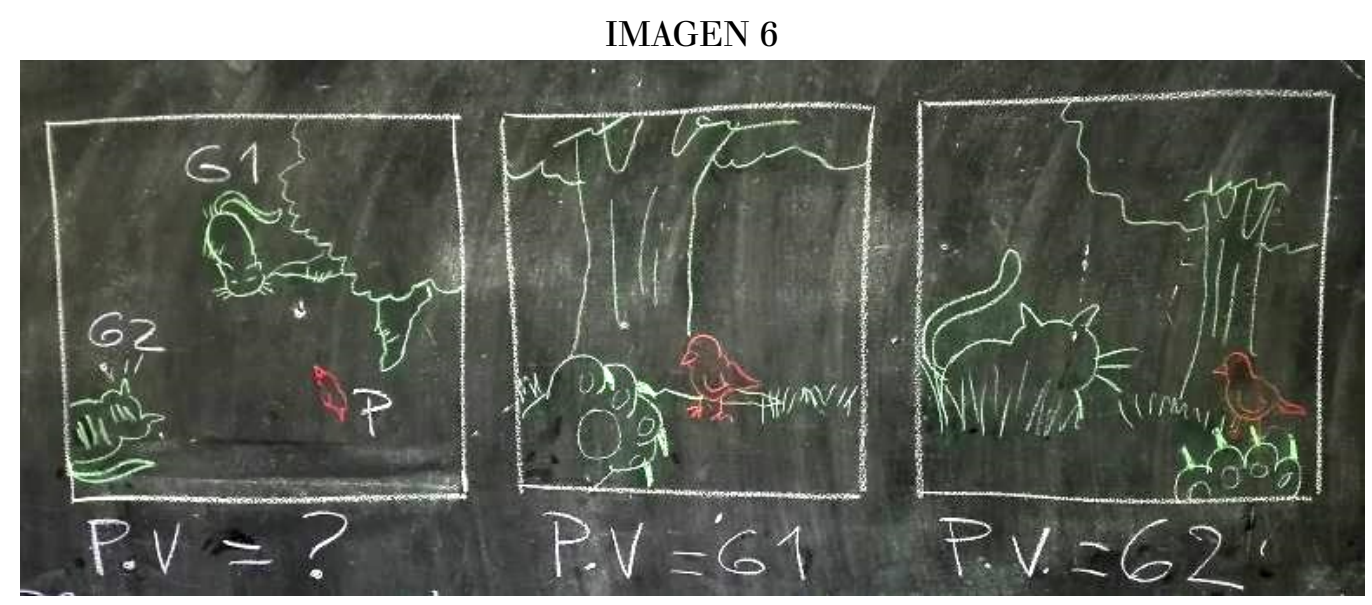

Fuente: elaboración propia.

Sobre un grupo de imágenes como la 5 se pidió a los alumnos suponer que las mismas correspondían a diferentes puntos de vista; debían, entonces expresar, qué tipo de personaje (humano o no) podría ser la fuente enunciativa o si no había "personaje". En caso de que creyeran que alguna de las imágenes no podía ser capturada por el ojo de ningún ser real, podían señalarlo y justificarlo. A partir de estas reflexione se sistematizaron los conceptos de narrador homodiegético y heterodiegético así como el de focalización.

\section{Consideraciones Finales}

La necesidad de adaptar las prácticas educativas frente a nuevas necesidades requiere, en muchos casos, la incorporación de herramientas y cuerpos de saber que se encuentran por fuera de las trayectorias formativas en que nos amparamos. Se abren así nuevas posibilidades pero también el arduo desafío de lograr incorporaciones para definir propuestas. ¿Cómo? ¿Por qué? ¿Para qué? Son algunos de los interrogantes a los cuales hemos tratado de responder en este trabajo.

Creemos que la articulación entre la disciplina escolar Lengua y Literatura y los abordajes de la cultura visual resultan auspiciosos por sus afinidades y el modo en que dan cuenta de la complejidad de lo que hoy entendemos por alfabetización, literacidad o prácticas de lectura y escritura frente a los cambios culturales.

\section{RefERENCiAS}

Aguirre, M. E. (2001). Enseñar con textos e imágenes. Una de las aportaciones de Juan Amós Comenio. Revista Electrónica de Investigación Educativa, 3(1). Recuperado de http://redie.uabc.mx/vol3nol/contenido-lora.ht $\mathrm{ml}$

Alvarado, M. (1995). Paratextos. Buenos Aires: Eudeba.

Alvarado, M. (2003). La resolución de problemas. Propuesta Educativa, 26(1), 1-6. Recuperado de https://goo.gl/h PDDNT

Amossy, R. y Herschberg Pierrot, A. (2001). Estereotipos y clichés. Buenos Aires: EUDEBA.

Acaso, M. (2006). El lenguaje visual. Barcelona: Paidós.

Angenot, M. (2010). El discurso social. Los límites históricos de lo pensable y lo decible. Buenos Aires: Siglo XXI.

Anguio, B. (2018). Artes Visuales: Herramientas de taller. Una propuesta didáctica para propiciar acciones creativas. Buenos Aires: Diseño.

Baptista Lucio, P., Fernández Collado, C. y Hernández Sampieri, R. (2006). Metodología de la Investigación. México DF: McGraw-Hill Interamericana. 
Barthes, R. (1970). Retórica de la imagen. En La semiología (pp. 127-140). Buenos Aires: Tiempo contemporáneo.

Belardinelli, P. y Catibiela, A. (2017). Consideraciones sobre el arte y su enseñanza. Apuntes de clase. Metal, 3(1), 75-85. Recuperado de https://goo.gl/YSsGDW

Beltrán, P. (2016). Utilizando memes con tus alumnos. Números, 91, 29-41. Recuperado de http://www.sinewton.o $\mathrm{rg} /$ numeros/numeros/91/Experaula.pdf

Chen, Y. H. y Ortiz, R. (2016). Valoración del uso de los memes en la adquisición del orden de los adjetivos. (Tesis de grado, Universidad de Carabobo). Carabobo, Venezuela. Recuperado de http://mriuc.bc.uc.edu.ve/handle/12 $3456789 / 4428$

Ciafardo, M. (2010). ¿Cuáles son nuestras sirenas? Aportes para enseñanza del lenguaje visual. Revista Iberoamericana de Educación, 52(2), 2-8. Recuperado de https://goo.gl/ZSEKwY

Cozzi, T. (2017). Reflexiones sobre la educación artística Consensos y disensos en torno a diferentes modelos de enseñar arte. (Tesis de Posgrado, Universidad Nacional de La Plata). La Plata, Argentina. Recuperado de http://sedici .unlp.edu.ar/handle/10915/85450

Cuesta, C. (2006). Discutir sentidos. La lectura literaria en la escuela. Buenos Aires: El Zorzal.

Cuesta, C. (2012). Lengua y Literatura: disciplina escolar. Hacia una metodología circunstanciada de su enseñanza (Tesis). La Plata, Facultad de Humanidades y Ciencias de la Educación, Universidad Nacional de La Plata. Recuperado de http://www.memoria.fahce.unlp.edu.ar/tesis/te.641/te.641.pdf

Cuesta, C. (2019). Didáctica de la lengua y la literatura, politicas educativas y trabajo docente. Problemas metodológicos de la enseñanza. Buenos Aires: Miño y Dávila.

Da Porta, E. (2015). Medios, tecnologías y redes. Recursos para el conocimiento y reconocimiento de sí. Avatares de la comunicación y la cultura, 9, 1-17.

Davini, M. C. (2008). Métodos de enseñanza.: didáctica general para maestros y profesores. Buenos Aires: Santillana.

DGCyE (2008). Diseño curricular para la educación secundaria, $2^{\circ}$ ES. La Plata, Dirección General de Cultura y Educación.

DGCyE (2010). Diseño curricular para la educación secundaria. Literatura $4^{\circ}$ ES. La Plata, Dirección General de Cultura y Educación.

Dussel, I. (2009). Escuela y cultura de la imagen: los nuevos desafíos. Nómadas, 30, 180-193.

Dussel, I. (2012, 4 de diciembre). Escuela y saberes en la cultura digital [Archivo de video]. Recuperado de https://w ww.youtube.com/watch?v=qRmsK7df9Wg

Gagliardi, L. (2016). La noticia periodística en la enseñanza de la Lengua y la Literatura: algunas resignificaciones. Ponencia presentada en las IV Jornadas Bilingües. Instituto Superior de Formación Docente No 97, La Plata, Argentina.

Gagliardi, L. (2017). Materiales didácticos para lengua y literatura: diseño y experiencias. I Jornada de Diseño y Narrativas Digitales. Experiencias y casos para el aprendizaje, 28 de octubre, La Plata, Buenos Aires, Argentina.

Gagliardi, L. (2020). Memes en la clase de lengua y literatura: Qué, para qué y cómo. Convergencias, 3(5), 25-49. Recuperado de http://www.memoria.fahce.unlp.edu.ar/art_revistas/pr.11612/pr.11612.pdf

García Delgado, J. (2018). El humor en el aula de español a través de los memes. Un enfoque didáctico (Tesis de maestría, CIESE-Comillas). Comillas, España.

Goldar, G. y Spolidoro, F. (2016). Reseña. Archivos de Ciencias de la Educación, 10(1). Recuperado de https://goo.g 1/ybhk9X

González López Ledesma, A. (2016). Los objetos de aprendizaje del Portal Educ.ar: inclusión de tecnologías digitales en materiales didácticos de lengua y literatura. Alabe, 13, 1-20. doi: 10.15645/Alabe2016.13.5

González López Ledesma, A. y Arias, G. (2014). Tipología de propuestas de abordaje de contenidos de Lengua y Literatura con inclusión de TIC. Apertura, 6(2), 1-9.

Hernández, F. (1996). Educación artística para la comprensión de la cultura visual. Qurriculum, 12-13, 11-27.

Hernández, F. (2010). Educación y cultura visual. Madrid: Octaedro. 
Kerbrat-Orecchioni, C. (1983). La connotación. Buenos Aires, Argentina: Hachette.

López Corral, M. y Moya, P. (2017). "iLlame ya!": Estrategias argumentativas y otros aspectos de la enseñanza de la lengua desde una aproximación multimodal. I Jornadas de Enseñanza de la Lengua, 31 de marzo y 1 de abril de 2017, Ensenada, Argentina. Ensenada: Universidad Nacional de La Plata. Disponible en http://www.memoria .fahce.unlp.edu.ar/trab_eventos/ev.10925/ev.10925.pdf

López García, M. (2015). Nosotros, vosotros, ellos. La variedad rioplatense en manuales escolares. Buenos Aires: Miño y Dávila.

Massarella, M. (2017). Los estructuralismos argentinos y la didáctica de la literatura: El caso de la enseñanza de la poesía en la escuela secundaria (Tesis). La Plata, Facultad de Humanidades y Ciencias de la Educación, Universidad Nacional de La Plata

Mattioli, L. (2012). Lo que se dice y se hace. Lo que se calla y se niega: Apropiaciones de la literatura en el aula. El Toldo de Astier, 3(4), 12-20. Recuperado de http://www.memoria.fahce.unlp.edu.ar/art_revistas/pr.5135/pr.5 135.pdf

ME (2006a). Núcleos de aprendizaje prioritarios. Lengua (ciclo básico) Buenos Aires: Ministerio de Educación.

ME (2006b). Núcleos de aprendizaje prioritarios. Lengua (ciclo orientado). Buenos Aires: Ministerio de Educación.

ME (2006c). Núcleos de aprendizaje prioritarios. Arte. Buenos Aires: Ministerio de Educación.

Mejía Echeverri, S. A. (2009). La educación artística como comprensión crítica de la cultura visual. (Pensamiento) (palabra) y obra, 1(1), 36-46. Recuperado de https://revistas.pedagogica.edu.co/index.php/revistafba/article/v iew/87/54

Mitzoreff, N. (1999). An Introduction to Visual Culture. Nueva York: Roultledge.

Navarro Spinach, G. (2011). "Cultura Visual y enseñanza de la historia. La percepción de la Edad Media”. Educación Artistica. Revista de Investigación, 2, 153-160.

RAE (1917). Diccionario de la lengua española. Madrid, España: Epasa.

Rockwell, E. (2009). La experiencia etnográfica. Historia y cultura en los procesos educativos. Buenos Aires: Paidós.

Viñao, A. (2002). Sistemas educativos, culturas escolares y reformas: continuidades y cambios. Madrid: Morata.

VVAA (2015). Tercero pisa fuerte. Antología. La Plata: EES No 46. Recuperado de https://goo.gl/DnzVpT

VVAA (2016). Lluvia de meteoritos. Antología. La Plata: EES No 46. Recuperado de https://goo.gl/DnzVpT

VVAA (2017). 24 lápices. Antología. La Plata: EES No 46. Recuperado de https://goo.gl/gLjqxW

\section{Notas}

1 Esto suele promoverse principalmente en reuniones plenarias de inicio de ciclo lectivo así como en encuentros de capacitación implementados en el marco de políticas públicas como el Programa Nacional de Formación Permanente (PNFP) del Ministerio de Educación y Cultura.

2 Esta distinción la tomamos de la antropóloga Elsie Rockwell (2009).

3 El modo en que son utilizadas las imágenes, en particular, dentro de las clases de Lengua y Literatura constituye un punto pendiente de investigación aún. Cuesta (2012, p. 246-247) refiere un caso que podríamos tomar como habitual del espacio curricular a partir de los testimonios esporádicos de docentes: la utilización imágenes (publicitarias) como modelo para escribir descripciones. López Corral y Moya (2017) analizan casos en que se utilizan las tapas de libros de literatura para trabajar cuestiones sobre las obras literarias.

4 Ciafardo (2010) desarrolla el impacto que tuvieron los desarrollos lingüísticos en la conformación de los estudios visuales y los obstáculos que estas analogías suponen.

5 Esto por supuesto deja de lado la existencia de imágenes visuales no icónicas como las imágenes abstractas.

6 Los nombres de los espacios curriculares han variado diacrónicamente. Hablaremos de Lengua y Literatura en adelante para aludir a un cuerpo de saber disciplinar y evitar, así, confusiones. Seguimos en esto la elección que plantea Cuesta (2019).

7 El conjunto de saberes comprendidos como "gramática" en su vertiente escolar ha sufrido contracciones y expansiones históricas. Véase Gagliardi (2016) para mayores detalles. 
8 Según Belardinelli y Catibiela (2017), el escolanovismo dio lugar a la expresión pero escaso o nulo sitio para el trabajo sobre contenidos bajo la idea de que la disciplina escolar acotaba la creatividad. Esa idea persiste en el sistema educativo durante décadas aún a pesar de las reformas curriculares (Mejía Echeverri, 2009).

9 Aparecen también dentro de la formación docente espacios como Semiótica y otros que buscan dar cuenta de las nuevas necesidades formativas para los docentes de Lengua y Literatura. Sin embargo, la inclusión de dichos espacios curriculares tuvo lugar más en los profesorados de institutos de formación docente que en los universitarios. Recordemos que las universidades cuentan con autonomía, por lo cual las reformas de planes de estudio de carreras como Letras o Lengua y Literatura no necesariamente respondieron a los lineamientos de la currícula para el nivel secundario ni incorporaran estos contenidos.

10 En Argentina, el sistema educativo se encuentra descentralizado. Por este motivo, si bien se sanciona un currículum nacional, el mismo dede ser tomado y adaptado en diseños curriculares de las jurisdicciones provinciales.

11 La publicación completa puede consultarse en https://goo.gl/5yV1sA

12 Los textos e ilustraciones producidos en el marco de esta secuencia pueden consultarse en VVAA, 2016 y 2017.

\section{BY-NC-SA}

